\title{
Groove Pancreatitis: Endoscopic Treatment via the Minor Papilla and Duct of Santorini Morphology
}

Tanyaporn Chantarojanasiri ${ }^{1,2}$, Hiroyuki Isayama ${ }^{1}$, Yousuke Nakai ${ }^{1}$, Saburo Matsubara ${ }^{1}$, Natsuyo Yamamoto ${ }^{3}$, Naminatsu Takahara ${ }^{1}$, Suguru Mizuno ${ }^{1}$, Tsuyoshi Hamada ${ }^{1,4}$, Hirofumi Kogure ${ }^{1}$, and Kazuhiko Koike ${ }^{1}$

${ }^{1}$ Department of Gastroenterology, Graduate School of Medicine, The University of Tokyo, Tokyo, Japan, ${ }^{2}$ Department of Internal Medicine, Police General Hospital, Bangkok, Thailand, ${ }^{3}$ Department of Gastroenterology, Toshiba General Hospital, Tokyo, Japan, and ${ }^{4}$ Department of Medical Oncology, Dana-Farber Cancer Institute, Harvard Medical School, Boston, MA, USA

Background/Aims: Groove pancreatitis (GP) is an uncommon disease involving the pancreaticoduodenal area. Possible pathogenesis includes obstructive pancreatitis in the duct of Santorini and impaired communication with the duct of Wirsung, minor papilla stenosis, and leakage causing inflammation. Limited data regarding endoscopic treatment have been published. Methods: Seven patients with GP receiving endoscopic treatment were reviewed. The morphology of the pancreatic duct was evaluated by a pancreatogram. Endoscopic dilation of the minor papilla and drainage of the duct of Santorini were performed. Results: There were two pancreatic divisum cases, one ansa pancreatica case and four impaired connections between the duct of Santorini and the main pancreatic duct. Three to 31 sessions of endoscopy, with 2 to 24 sessions of transpapillary stenting and dilation, were performed. Interventions through the minor papilla were successfully performed in six of seven cases. The pancreatic stenting duration ranged from 2 to 87 months. Five patients with evidence of chronic pancreatitis (CP) tended to receive more endoscopic interventions than did the two patients without CP (2-24 vs 2, respectively) for GP and other complications associated with CP. Conclusions: Disconnection or impairment of communication between the ducts of Santorini and Wirsung was observed in all cases of GP. No surgery was required, and endoscopic minor papilla dilation and drainage of the duct of Santorini were feasible for the treatment of GP. (Gut Liver 2018;12:208-213)

Key Words: Groove pancreatitis; Endoscopic treatment; Pancreatic ducts; Paraduodenal pancreatitis

\section{INTRODUCTION}

Groove pancreatitis is a term used for the description of the segmental inflammatory lesion involving the space between the pancreatic head, the duodenum and the common bile duct, though various terminology of this condition has been proposed including paraduodenal pancreatitis, cystic dystrophy of heterotopic pancreas, paraduodenal wall cyst, pancreatic hamartoma of duodenum and myoadenomatosis. The disease is uncommon but accounts for $12.8 \%$ to $19.5 \%$ of pancreatoduodenectomy performed for chronic pancreatitis ${ }^{1,2}$ due to failure of conservative treatment or misdiagnosis as pancreatic cancer. On the other hand, there have been few reports on endoscopic treatment for groove pancreatitis including cystoenterostomy, pancreatic or biliary sphincterotomy with stent placement and duodenal dilation. ${ }^{3-5}$ In this study, we aimed to demonstrate the role of the endoscopic treatment for groove pancreatitis, especially pancreatic duct drainage via minor papilla, and its long-term outcomes. In addition, the morphology of duct of Santorini was evaluated to clarify the pathophysiology of this disease in relation to the endoscopic treatment via the minor papilla.

\section{MATERIALS AND METHODS}

Data on consecutive patients who received endoscopic treatment for groove pancreatitis in a tertiary institute between April 1999 and September 2016 were retrospectively studied. The diagnosis of groove pancreatitis was made based on the history of pancreatitis together with typical imaging findings (Fig. 1) such as a mass in the pancreatoduodenal groove, duodenal wall thickening, and/or multiloculated cyst around the groove area on computed tomography (CT) scan, magnetic resonance

Correspondence to: Hiroyuki Isayama

Department of Gastroenterology, Graduate School of Medicine, The University of Tokyo, 7-3-1 Hongo, Bunkyo-ku, Tokyo 113-8655, Japan

Tel: +81-3-3815-5411, Fax: +81-3-5800-9801, E-mail: isayama-tky@umin.ac.jp

Received on April 5, 2017. Revised on June 14, 2017. Accepted on June 26, 2017. Published online December 8, 2017

pISSN 1976-2283 eISSN 2005-1212 https://doi.org/10.5009/gnl17170

@ This is an Open Access article distributed under the terms of the Creative Commons Attribution Non-Commercial License (http://creativecommons.org/licenses/by-nc/4.0) which permits unrestricted non-commercial use, distribution, and reproduction in any medium, provided the original work is properly cited. 
imaging (MRI) or endoscopic ultrasound (EUS). The concurrent presence of chronic pancreatitis was defined by the presence of characteristic imaging for chronic pancreatitis, such as main pancreatic duct dilation, pancreatic parenchymal atrophy and pancreatic calcification on the CT, or histologic findings and/or history of repeated upper abdominal pain, abnormal pancreatic enzyme, abnormal pancreatic exocrine function or continuous alcohol consumption of more than $80 \mathrm{~g} /$ day as proposed by Japan Pancreas Society. ${ }^{6}$ The response to treatment was evaluated including the clinical response; i.e., the improvement of symptoms (pancreatitis or duodenal obstruction) and the imaging response; i.e., the improvement of pancreatic duct stricture with upstream dilation, or the resolution of duodenal wall thickening, a mass-like lesion or a cystic lesion as demonstrated prior to the endoscopic treatment.

Endoscopic retrograde pancreatography (ERP) was performed under conscious sedation. After the duodenoscope intubation into the second portion of the duodenum, pancreatogram through the major and minor papilla were performed followed by guidewire insertion into the pancreatic duct for further interventions. In cases with failed cannulation via the minor papilla,

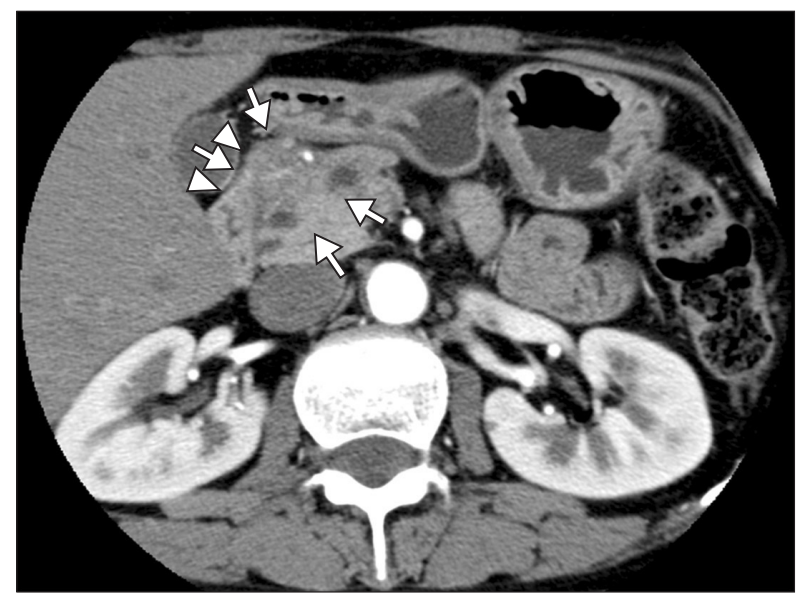

Fig. 1. Computed tomography of a patient with groove pancreatitis showing a mass-like, solid-cystic lesion at the pancreaticoduodenal groove (arrows) with duodenal wall thickening (arrowheads). the rendezvous technique was utilized: The major papilla was cannulated and the guidewire was inserted in an anterograde manner through the minor papilla. Then, the minor papilla was cannulated with a catheter preloaded with a guidewire along the first guidewire (Fig. 2). The pancreatic duct dilation with or without pancreatic duct stenting was performed at the discretion of the attending physician. Endoscopic minor papilla dilation was performed using a 4 to $6 \mathrm{~mm}$ PET balloon (Conmed Endoscopic Technologies, Billerica, MA, USA) or Hurricane balloon dilator (Boston Scientific, Natick, MA, USA). For pancreatic duct drainage, either a plastic stent or a temporary nasopancreatic drainage tube was selected. In cases with pancreatic stent placement, ERP was scheduled every 2 to 3 months for stent exchange and re-evaluation of the pancreatic duct. Stent removal was attempted in cases with resolution of pancreatic duct stricture or leakage. The number of ERP sessions was evaluated both within 6 months after the first endoscopic session and throughout the clinical course to determine the persistence of pancreatic duct stricture. The number of endoscopic interventions, such as balloon dilation or stenting, was also evaluated. The study was performed in accordance with the principles of the Declaration of Helsinki. The written informed consents were obtained in all patients prior to the procedure.

\section{RESULTS}

\section{Patient characteristics}

Patients' demographic data are shown in Table 1. A total of seven cases (6 males) undergoing endoscopic treatment for groove pancreatitis were identified with a median age of 58 years. All cases presented with clinical symptoms of pancreatitis, with one case of concurrent symptoms of duodenal obstruction. All patients were smokers and had chronic alcohol consumption, and five patients had evidence of chronic pancreatitis on CT or EUS. One patient underwent EUS-guided transmural drainage for a symptomatic pancreatic pseudocyst prior to transpapillary pancreatic duct drainage. As the clinical presentations of groove pancreatitis and pancreatic cancer overlap, ${ }^{7}$ during endoscopic treatment, exclusion of pancreatic
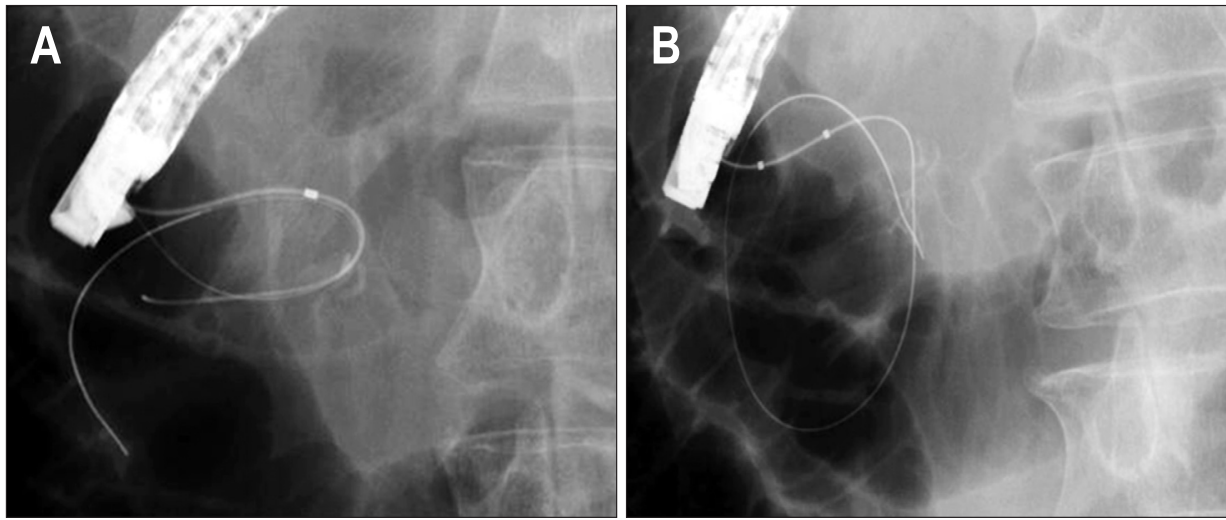

Fig. 2. Minor papilla access was performed using the rendezvous technique (case 3). The major papilla was cannulated, and the guidewire was inserted in an anterograde manner through the minor papilla and coiled inside the duodenal lumen (A). Retrograde access was achieved using a cannulation catheter preloaded with another guidewire inserted alongside with the first guidewire, which was removed after successful minor papilla cannulation. In this session, balloon dilation of the minor papilla was performed over the minor papilla (B). 


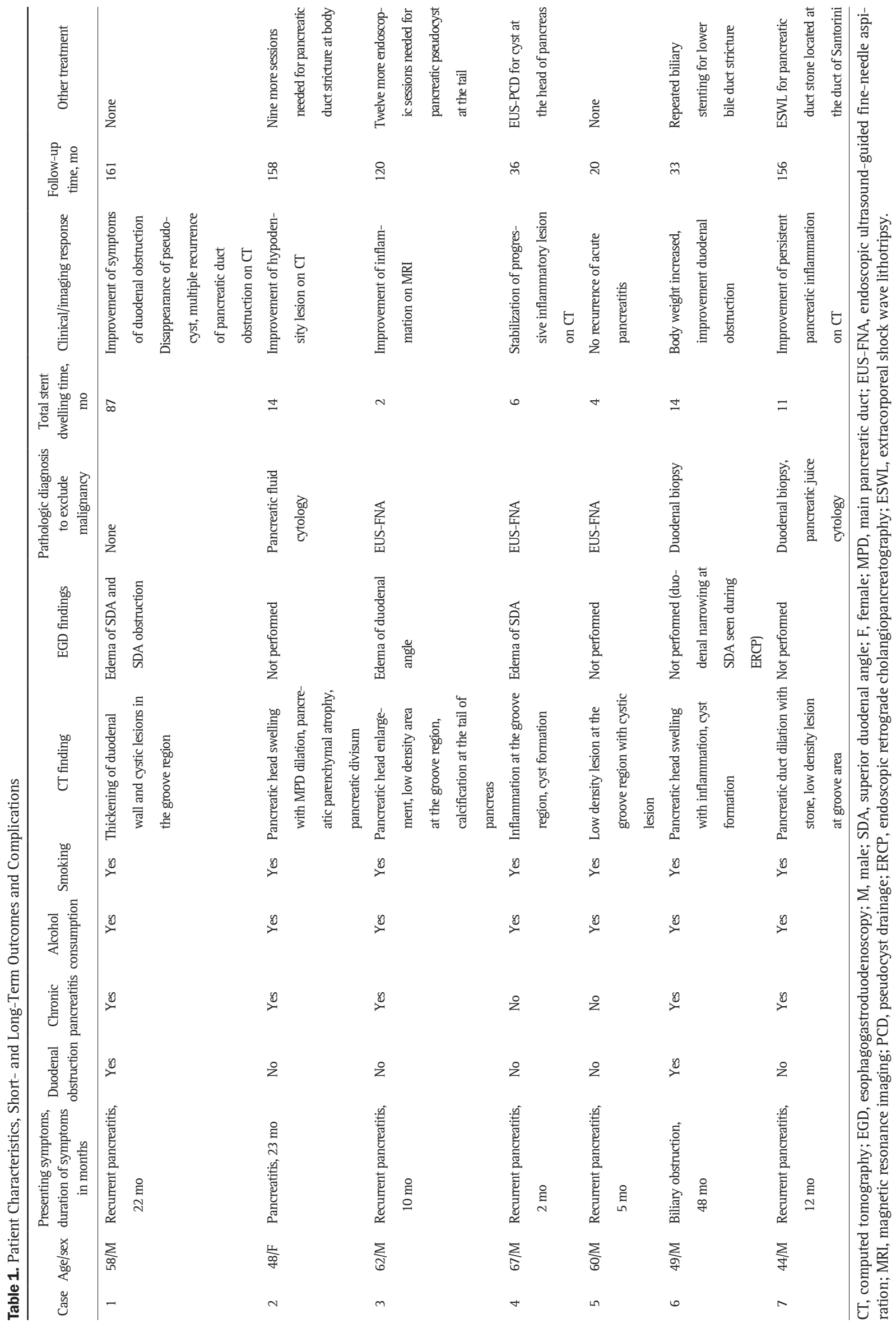


malignancy was performed using EUS fine-needle aspiration in three cases, pancreatic duct brush cytology in one case, and direct biopsy in one case as shown in Table 1. In the remaining case, follow-up imaging together with the chronicity of the symptoms made malignancy less likely. The median duration of clinical symptoms of pancreatitis prior to endoscopic treatment was 12 months (range, 2 to 48 months).

\section{Endoscopic findings and management}

The endoscopic findings and treatment are described in Table 1. The patterns of the pancreatic duct is demonstrated in Fig. 3; two pancreatic divisum, one ansa pancreatica and four impaired connection between the duct of Santorini and the main pancreatic duct. The leakage of contrast medium from the duct of Santorini with pseudocyst formation at the pancreatic head was seen in three cases.

Endoscopic drainage via the minor papilla was attempted in all cases but primary minor papilla cannulation was unsuccessful in four cases. The cannulation using a rendezvous technique from the duct of Wirsung was successfully performed in three patients but the guidewire was unable to pass through the minor papilla in one case (case 5) despite multiple attempts and the stent was subsequently inserted through the major papilla. As a result, pancreatic duct stent placement was performed via the minor papilla in six cases and via the major papilla in one case. The size of pancreatic duct stent varied from 5 to 7-F depending on the endoscopists' decision during each ERP sessions. In cases 2 and 3, further endoscopic sessions were performed for the pancreatic duct stricture at the body and the pseudocyst located distant from the paraduodenal region and the endoscopic procedures were performed for benign biliary stricture in one case (case 6). No transmural pancreatic duct drainage, percutaneous drainage, or surgery was performed in any patients. There were three adverse events related to endoscopic retrograde cholangiopancreatography procedure: two stent migration and one case of mild post-ERP pancreatitis.

\section{Long-term outcomes}

The median follow-up time ranged from 20 to 161 months and the median stent dwelling time was 11 months (range, 2 to

\begin{tabular}{|c|c|c|c|c|c|c|c|c|c|c|c|c|c|}
\hline \multirow[t]{2}{*}{ Case } & \multirow[t]{2}{*}{ ERCP } & \multirow[t]{2}{*}{ Scheme } & \multicolumn{6}{|c|}{ ERP finding } & \multicolumn{5}{|c|}{ ERP intervention } \\
\hline & & & $\begin{array}{l}\text { Main PD } \\
\text { dilation }\end{array}$ & $\begin{array}{l}\text { Main PD } \\
\text { stricture }\end{array}$ & $\begin{array}{c}\text { Cyst } \\
\text { (location) }\end{array}$ & $\begin{array}{l}\text { Minor } \\
\text { PD } \\
\text { leakage }\end{array}$ & $\begin{array}{l}\text { Minor } \\
\text { PD } \\
\text { stricture }\end{array}$ & $\begin{array}{l}\text { Minor and } \\
\text { major PD } \\
\text { connection }\end{array}$ & Comment & $\begin{array}{l}\text { ERP within } \\
6 \mathrm{mo} / \\
\text { total }\end{array}$ & $\begin{array}{c}\text { No. of } \\
\text { pancreatic } \\
\text { interventions } \\
\text { (balloon } \\
\text { dilation/stenting) } \\
\text { within } 6 \\
\text { mo/total }\end{array}$ & $\begin{array}{c}\text { PD stenting } \\
\text { (major or minor } \\
\text { papilla) }\end{array}$ & Comment \\
\hline 1 & & & No & No & $\begin{array}{c}\text { Yes } \\
\text { (head) }\end{array}$ & Yes & Yes & Disconnected & $\begin{array}{l}\text { Cystic lesion and } \\
\text { contrast leakage } \\
\text { from the duct of } \\
\text { Santorini }\end{array}$ & $4 / 31^{*}$ & $3 / 24$ & Minor & $\begin{array}{l}\text { Direct minor papilla } \\
\text { cannulation and } \\
\text { drainage of cysts }\end{array}$ \\
\hline 2 & & & Yes & Yes & No & No & Yes & Disconnected & Pancreatic divisum & $4 / 11$ & $4 / 9$ & Minor & $\begin{array}{l}\text { Direct minor papilla } \\
\text { cannulation }\end{array}$ \\
\hline 3 & & & No & Yes & $\begin{array}{l}\text { Yes } \\
\text { (body) }\end{array}$ & No & Yes & $\begin{array}{l}\text { Impaired due } \\
\text { to connecting } \\
\text { duct stricture }\end{array}$ & - & $3 / 3$ & $2 / 2$ & Minor & $\begin{array}{l}\text { Rendezvous through the } \\
\text { major papilla }\end{array}$ \\
\hline 4 & & & No & No & $\begin{array}{c}\text { Yes } \\
\text { (head) }\end{array}$ & No & No & $\begin{array}{l}\text { Impaired due } \\
\text { to connecting } \\
\text { duct stricture }\end{array}$ & - & $4 / 4$ & $2 / 2$ & Minor & $\begin{array}{l}\text { Endoscopic drainage of } \\
\text { pseudocyst prior to the } \\
\text { PD intervention }\end{array}$ \\
\hline 5 & & & No & No & $\begin{array}{l}\text { Yes } \\
\text { (head) }\end{array}$ & No & Yes & $\begin{array}{l}\text { Impaired due } \\
\text { to connecting } \\
\text { duct stricture }\end{array}$ & Ansa pancreatica & $4 / 4$ & $2 / 2$ & Major $\mathrm{F}$ & $\begin{array}{l}\text { Rendezvous through the } \\
\text { major papilla }\end{array}$ \\
\hline 6 & & & Yes & Yes & Yes & Yes & Yes & Disconnected & - & $3 / 5$ & $2 / 2$ & Minor $\quad \mathrm{F}$ & $\begin{array}{l}\text { Rendezvous through the } \\
\text { major papilla }\end{array}$ \\
\hline 7 & & & Yes & Yes & Yes & Yes & Yes & $\begin{array}{l}\text { Impaired due } \\
\text { to stricture } \\
\text { and stone }\end{array}$ & & $5 / 5$ & $1 / 1$ & Minor & $\begin{array}{l}\text { ESWL for pancreatic } \\
\text { duct stone prior to } \\
\text { minor papilla stenting }\end{array}$ \\
\hline
\end{tabular}

Fig. 3. Endoscopic retrograde pancreatogram (ERP) showing the pattern of the minor pancreatic duct (arrow showing the connection between the ducts of Wirsung and Santorini). The ERP findings and ERP interventions are demonstrated.

ERCP, endoscopic retrograde cholangiopancreatography; PD, pancreatic duct; ESWL, extracorporeal shock wave lithotripsy. *The patient experienced recurrent pancreatitis. 
87 months) (Table 1). The median total number of session was 5 (range, 3 to 31), with a median of 4 sessions (range, 3 to 5) performed within the first 6 months. Five cases achieved both clinical and image response, i.e., the resolution of inflammatory or cystic change and the other two cases achieved clinical responses, i.e., no recurrence of acute pancreatitis and improvement of duodenal obstruction, despite the lack of image response. The stent dwelling time was different according to the presence of chronic pancreatitis: 5 months versus 14 months in cases without and with chronic pancreatitis. Additional endoscopic treatments, such as pancreatic duct dilation and stenting for main pancreatic duct obstruction and pseudocyst formation at distant location from the pancreaticoduodenal groove were performed. One case who was followed for 161 months achieved clinical response after 22 endoscopy sessions and remained stent-free for 16 months, but developed recurrent acute pancreatitis, necessitating further endoscopic treatment. Up to the present, all patients remained stent-free for a median of 36 months (range, 19 to 144 months) and no pancreatic cancer was seen during the follow-up period.

\section{DISCUSSION}

Our study suggested that the impaired drainage in the duct of Santorini contributed to the pathogenesis of groove pancreatitis. Endoscopic treatment via the minor papilla was successful in six out of seven cases in our study population. Despite the lack of established treatment strategy for groove pancreatitis due to its low prevalence and various clinical presentations, endoscopic drainage of the minor papilla can be a less invasive treatment option compared to surgical treatment.

Most reports demonstrated close correlation of groove pancreatitis with the history of alcoholism and smoking as seen in our cohort. ${ }^{8}$ However, the pathogenesis is still unclear. Several studies demonstrated the pathophysiology involving the functional obstruction of the minor papilla ${ }^{9}$ and proliferation of myeloid cells and neural cells together with fibrosis centered in the region of minor papilla. ${ }^{9}$ Protein plugs, calcifications, and abscess of the duct of Santorini were also demonstrated. ${ }^{10}$ Thus, we believe the common feature of groove pancreatitis with various clinical presentations is the stagnancy of pancreatic juice of the duct of Santorini, which in turns causes leakage of the pancreatic juice into the groove area. In our study cohort, pancreatogram showed two pancreatic divisum and one ansa pancreatica. In the remaining four cases, the PD stricture was seen either in the duct of Santorini or at the junction of the ducts of Santorini and Wirsung, though it is unclear whether the stricture was the cause or the result of pancreatitis. Interestingly, we also experienced minor pancreatic duct leakage in one case and pseudocyst connected to the minor pancreatic duct in two cases. These findings implied a close relationship between the duct of Santorini pathology and the pathogenesis of the disease and our strategy of draining pancreatic juice through the minor papilla and dilating the stricture by a PD stent appeared to be an effective management for groove pancreatitis. ${ }^{4}$ Our results were encouraging when compared to the technical success rate of $57.9 \%$ by the endoscopic approach with the need for salvage surgery in $31.6 \%(6 / 19)$ in the previous report. ${ }^{3}$ However, a large scale study is warranted to confirm our preliminary results.

Endoscopic pancreatic duct interventions and stenting have become the treatment strategy for patients with pancreatic duct stricture. ${ }^{11}$ However, endoscopic pancreatic duct interventions through the minor papilla have been reported mostly in the setting of major papilla obstruction and pancreatic divisum. ${ }^{12-14}$ Previous report from our institute demonstrated that the use of balloon dilation, nasopancreatic drainage, or pancreatic duct stent placement through the minor papilla were effective for symptomatic pancreatic divisum. ${ }^{13}$ This data also applied to our treatment rationale for abnormal findings of the duct of Santorini. Despite many publications of surgical treatment for groove pancreatitis, in our study, all patients were successfully treated by endoscopic approach. ERP through the minor papilla can be technically demanding especially in the presence of duodenal involvement by groove pancreatitis but our approach utilizing a rendezvous approach from the duct of Wirsung was useful in three out of four attempted cases. The number of ERP intervention ranged from 2 in those without evidence of concurrent chronic pancreatitis, to 24 sessions in the case with chronic pancreatitis. Most of the endoscopic sessions were performed during the first 6 months. In those without chronic pancreatitis, no further treatment for the paraduodenal lesions was needed after the first 6 months, indicating the reversible inflammatory process in this region. On the other hand, more endoscopic sessions were subsequently necessary in those with chronic pancreatitis with established fibrotic process causing a persistent pancreatic duct stricture. This demonstrated the difference in treatment strategy based on the background of chronic pancreatitis. Even though the groove pancreatitis has been proposed to be a type of chronic pancreatitis, co-existing diffuse chronic pancreatitis in this condition is not a rule, ${ }^{6}$ with approximately $70 \%$ of these patients having evidence of chronic pancreatitis, mostly related to alcohol consumption as reported in a large case series. ${ }^{3}$ In our series, five out of seven patients (71.4\%) had an evidence of chronic pancreatitis on CT. The natural course of these patients was different from those without evidence of chronic pancreatitis. Our hypothesis based on our results is that groove pancreatitis in those without $\mathrm{CP}$ might be caused by a reversible, inflammatory process alone, which has a chance of prompt recovery after a few sessions of endoscopic intervention. On the other hand, in those with $\mathrm{CP}$, the process is rather fibrotic and has become irreversible. ${ }^{7}$ Apart from the difference in background chronic pancreatitis, the number of endoscopic session seems to be less in those with shorter duration of symptom. 
Our main limitations are the retrospective study design and the limited number of patients according to the low prevalence of this disease. Despite the limited data, the difference of natural history between those with and without chronic pancreatitis could be demonstrated. However, there is still some controversy, as a large retrospective study did not find a clear relation of minor papilla abnormalities with this condition. ${ }^{15}$

In conclusion, we demonstrated the role of endoscopic pancreatic duct drainage via the minor papilla for the treatment of groove pancreatitis. In those with the presence of chronic pancreatitis, the number of endoscopic treatment session tends to be higher and the treatment may overlap with that of chronic pancreatitis. From our analysis of pancreatogram, the pathogenesis of groove pancreatitis was pancreatic juice stagnancy in the duct of Santorini. More studies are needed to confirm this hypothesis.

\section{CONFLICTS OF INTEREST}

No potential conflict of interest relevant to this article was reported.

\section{REFERENCES}

1. Becker V, Mischke U. Groove pancreatitis. Int J Pancreatol 1991;10:173-182.

2. Adsay NV, Zamboni G. Paraduodenal pancreatitis: a clinicopathologically distinct entity unifying "cystic dystrophy of heterotopic pancreas", "para-duodenal wall cyst", and "groove pancreatitis”. Semin Diagn Pathol 2004;21:247-254.

3. Arvanitakis M, Rigaux J, Toussaint E, et al. Endotherapy for paraduodenal pancreatitis: a large retrospective case series. Endoscopy 2014;46:580-587.

4. Isayama H, Kawabe T, Komatsu Y, et al. Successful treatment for groove pancreatitis by endoscopic drainage via the minor papilla. Gastrointest Endosc 2005;61:175-178.
5. Kager LM, Lekkerkerker SJ, Arvanitakis M, et al. Outcomes after conservative, endoscopic, and surgical treatment of groove pancreatitis: a systematic review. J Clin Gastroenterol 2017;51:749754.

6. Shimosegawa T, Kataoka K, Kamisawa T, et al. The revised Japanese clinical diagnostic criteria for chronic pancreatitis. J Gastroenterol 2010;45:584-591.

7. Lekkerkerker SJ, Nio CY, Issa Y, et al. Clinical outcomes and prevalence of cancer in patients with possible groove pancreatitis. J Gastroenterol Hepatol 2016;31:1895-1900.

8. Oza VM, Skeans JM, Muscarella P, et al. Groove pancreatitis, a masquerading yet distinct clinicopathological entity: analysis of risk factors and differentiation. Pancreas 2015;44:901-908.

9. Shudo R, Obara T, Tanno S, et al. Segmental groove pancreatitis accompanied by protein plugs in Santorini's duct. J Gastroenterol 1998;33:289-294.

10. Casetti L, Bassi C, Salvia R, et al. "Paraduodenal" pancreatitis: results of surgery on 58 consecutives patients from a single institution. World J Surg 2009;33:2664-2669.

11. Sasahira N, Tada M, Isayama H, et al. Outcomes after clearance of pancreatic stones with or without pancreatic stenting. J Gastroenterol 2007;42:63-69.

12. Fujimori N, Igarashi H, Asou A, et al. Endoscopic approach through the minor papilla for the management of pancreatic diseases. World J Gastrointest Endosc 2013;5:81-88.

13. Yamamoto N, Isayama $\mathrm{H}$, Sasahira $\mathrm{N}$, et al. Endoscopic minor papilla balloon dilation for the treatment of symptomatic pancreas divisum. Pancreas 2014;43:927-930.

14. Brown NG, Howell DA, Brauer BC, Walker J, Wani S, Shah RJ. Minor papilla endotherapy in patients with ventral duct obstruction: identification and management. Gastrointest Endosc 2017;85:365370.

15. Wagner M, Vullierme MP, Rebours V, et al. Cystic form of paraduodenal pancreatitis (cystic dystrophy in heterotopic pancreas (CDHP)): a potential link with minor papilla abnormalities? A study in a large series. Eur Radiol 2016;26:199-205. 